\title{
DISCURSOS CONSERVADORES NAS POLÍTICAS CURRICULARES: Do sacerdócio à profissionalização docente
}

Veronica Borges de Oliveira ${ }^{(*)}$

Assumiram ares de lugar-comum afirmações de há as posturas ditas conservadoras e/ou posturas que expressam apego às forças instituídas ligadas à escola, à religião, à justiça, em contraponto às posturas ditas progressistas. Não por acaso, produz-se um imaginário do senso comum, que fortalece a percepção (falseada) de que vivemos numa sociedade partida, com recorrente predomínio de uma lógica binária cujos pares em oposição representam o social. Essa agenda se propaga em diversos setores da sociedade notadamente no campo da educação e das políticas curriculares. Neste artigo, refuto esses modos de compreensão e proponho outras estratégias para compreender as possibilidades de dar sentido ao que nos circunda.

Sendo assim, invisto em uma possibilidade de operar com a perspectiva discursiva evocando a interrupção de uma concepção de linguagem aprisionada em sentidos como sucessividade/ linearidade, com pretensões representacionais e que toma a realidade como um dado objetivo e transparente. Com isso, destaco que esta investigação de sentidos das políticas curriculares, na perspectiva discursiva, possibilita a reativação de discursos que bloqueiam e/ou afirmam determinada política e como estes estão marcados pela contingência (LACLAU, 1990; HOWARTH, 2000; LOPES, 2015).

Considero estratégico rejeitar a lógica binária para compreender o social e o político. Essa visão divide o mundo em polos opostos, inviabiliza e/ou simplifica o debate quando esconde os elos perdidos entre as várias articulações políticas que deram/estabeleceram as condições de existência de determinada prática discursiva. Os processos de naturalização de hegemonias promovem, em grande medida, o recrudescimento dos discursos e fortalecem formas mais autoritárias, criando condições para manter seu status de "verdade".

Assim, com vistas a problematizar discursos conservadores no campo educativo, mais especificamente no campo das políticas curriculares para formação de professores, parto de uma

\footnotetext{
${ }^{(*)}$ Professora Adjunta no Departamento de Educação Aplicado ao Ensino (DEAE) da Faculdade de Educação da Universidade do Estado do Rio de Janeiro (UERJ). É mestre em Educação pela Universidade Federal Fluminense (UFF, 2008); doutora pela Progama de Educação ProPEd/UERJ e pesquisadora no Grupo de Pesquisa do CNPq Discursos sobre avaliação nas Políticas de Currículo para a Formação e o Trabalho Docente no Espaço Ibero-Americano.
} 
investigação dos processos de sedimentação que se deslocaram do discurso do sacerdócio ao da profissionalização docente reedificando posições conservadoras ainda que, em alguns momentos, essas posições marcadamente conservadoras tenham sido rejeitadas. Os significantes sacerdócio e profissionalização docente carreiam sentidos a partir de articulações discursivas que, invariavelmente, se apresentam num duplo movimento - estabilização e abertura de sentidos.

\section{SITUANDO ASPECTOS TEÓRICO-ESTRATÉGICOS DA INVESTIGAÇÃO}

Este artigo decorre da investigação empreendida durante o Doutorado em Educação no ProPEd/UERJ. ${ }^{1}$ A opção teórico-estratégica está baseada em aportes pós-fundacionais e pósestruturais (LACLAU, 1990; HOWARTH, 2000; STAVRAKAKIS, 2007; BALL, 1994; MARCHART, 2007) incorporados no campo da educação notadamente nos campos do currículo e formação de professores (LOPES, 2015; MACEDO, 2012; DIAS, 2012; CUNHA, LOPES, 2013; OLIVEIRA, 2012; CRAVEIRO, 2014; LOPES, BORGES, 2015).

Não tive a pretensão de fazer um levantamento exaustivo desses significantes. Com isso, assumo a impossibilidade de apreender a totalidade de discursos que envolvem os significantes “profissionalização docente" e "sacerdócio", menos por impossibilidade de cunho pragmático e mais por impossibilidade teórico-estratégica concernente à perspectiva discursiva.

O material empírico utilizado foram artigos selecionados no portal da $\mathrm{CAPES}^{2}$ a partir das palavras-chave "profissionalização docente", "profissionalidade docente", "trabalho docente", "profissão docente", “ofício docente”. Foram descartados os artigos em outras línguas e os que não contemplavam a temática apesar de serem sugeridos pelas buscas. Os artigos selecionados (vide referências) têm diferentes níveis de discussão, sendo uns mais superficiais e outros mais aprofundados e fazem articulações bastante peculiares com a problemática investigada.

Com Marchart (2007), compreendo "o político desde uma dimensão ontológica que transcende aos domínios da política” (LOPES, CUNHA e COSTA, 2013). Laclau e Mouffe, além de questionarem o universalismo das políticas ao afirmarem que um particular é alçado à condição

\footnotetext{
${ }^{1}$ Este artigo traz discussões da tese de Doutorado intitulada "Espectros da profissionalização docente nas políticas curriculares para formação de professores: um self para o futuro professor" sob a orientação e se insere na pesquisa "Políticas de Currículo em uma perspectiva discursiva" sob orientação da professora Alice C. Lopes, realizada no Programa de Pós-graduação em Educação (ProPEd/UERJ) na linha de pesquisa Currículo: sujeitos, conhecimento e cultura.

${ }^{2}$ O Portal de Periódicos da Capes é uma biblioteca virtual que reúne conteúdo científico disponível à comunidade acadêmico-científica brasileira. Divulga e dá acesso aos recentes artigos de pesquisadores brasileiros de vários campos do saber publicados nos periódicos de maior circulação, registrados nas bases SCIELO, PEPSIC e LIVRE.
} 
de universal, realçam o caráter contingencial dos processos discursivos (LACLAU, 1990, 2011, LACLAU; MOUFFE, 2010). Ressaltam, desse modo, que processos hegemônicos como os processos discursivos são marcados pela contingência, provisoriedade e precariedade. Reconfiguram também a concepção de sujeito/subjetividade operando com processos de identificação/subjetivação incorporados da psicanálise lacaniana e dando a ver que o sujeito já chega ao mundo nomeado, assujeitado à linguagem, portanto. Nessa concepção não é possível estabelecer uma a relação especular representante/representado - opera-se uma disjunção em pares binários. (STAVRAKAKIS, 2007; FINK, 1998; LACLAU, 1990;BIGLIERI; PERELLO, 2012).

Perspectivas conservadoras tendem a defenderem tanto a materialidade/objetividade na/da política bem como a concepção de sujeito do conhecimento (concebem o mundo via racionalidade). A fim de interpelar o conservadorismo, trago discursos que aliam sacerdócio à profissionalização docente. À primeira vista, discursos superados no campo da formação docente. No entanto, seria anacrônico descartar a existência de discursos pró-voluntariado ou mesmo do sacerdócio docente nas políticas curriculares para formação de professores (LOPES, MACEDO, TURA, 2012).

Compreender as políticas curriculares como práticas discursivas, para além da compreensão de que seriam normas a serem implementadas, implica interpelar a razoabilidade defendida por aqueles que se apegam ao caráter representativo das políticas curriculares. Os projetos de sociedade são constituídos de forma contingente na medida em que as regras, quando postas em ação, ganham outra configuração e são desconstruídas em função de outras tomadas de decisões (LOPES, 2012, p. 713).

Os discursos ditos conservadores apegam-se às instituições, operando com o racional de que estas (as instituições) são guardiãs dos fundamentos sólidos, que seguem proposições de caráter universal e que trazem em si um caráter necessário. A partir de aspectos incorporados da TD (LACLAU, 1990; LOPES, 2012, 2015) como o conceito de contingência radical favorece a interpelação de posicionamentos que escondem os pressupostos nos quais se apoiam e, mais do que isso, suprimem outras possibilidades que foram bloqueadas para que as posições que se tornaram hegemônicas tivessem passagem.

\section{REATIVAÇÕES DOS DISCURSOS DO SACERDÓCIO DOCENTE}

Tomemos o discurso do sacerdócio, uma formação discursiva que se articula, ora expulsando ora acolhendo demandas sociais que se aglutinam em torno desse nome. Esse nome é um significante vazio (LACLAU, 2011) que se esvazia de sentidos com vistas a tornar-se cada vez 
mais inespecífico e a abrigar, sob este significante, maiores possibilidades de demandas. Funcionando como significante vazio, o sacerdócio docente segue (ainda hoje) sendo capaz de alavancar sentidos e mobilizar diferentes disputas no campo discursivo da formação docente. Vale ressaltar que, de acordo com a investigação realizada, esse significante foi ressignificado pela profissionalização docente mantendo demandas de setores ditos conservadores.

Considerando documentos analisados ${ }^{3}$ (NÓVOA, 1991, 1995; FERREIRA, 2009; LOPES, 2012; PASCHOALINO, OLIVEIRA, ROCHA, 2011), é recorrente e faz parte do imaginário social, tanto na sociedade em geral como na categoria de professores em particular, a ideia de que o professor cumpre uma missão (muitas vezes da ordem do divino) em seu ofício. Vários autores citados creditam a isso às influências diretas do universo religioso e que tal processo produz modos de subjetivação do professor.

António Nóvoa analisou a trajetória da profissão docente em Portugal e se tornou referência dessa temática também no Brasil. Segundo ele, houve um deslocamento da tutela da Igreja para a tutela do Estado sobre os professores, com rupturas e continuidades entre estes dois modelos de ser professor. A princípio, ao longo do século XVII, consolida-se uma imagem do professor que se pauta no apostolado, na devoção, na vocação e no sacerdócio. Humildade e obediência são preceitos a serem seguidos, além disso, há valorização da pessoa humana em uma busca das características intrínsecas ao "bom” professor (NÓVOA, 1991, 1995).

Ainda segundo Nóvoa a profissão professor configura-se a partir de um fazer não especializado e exercido como segunda função, como uma doação de pessoas leigas ou de religiosos que, caridosamente, oferecem ensinamentos a outrem. Um efeito dessa estreita relação foi que os professores tomaram para si uma "ética e um sistema normativo essencialmente religiosos" (NÓVOA, 1991, p. 13). Os traços dessa lógica seguem subjetivando os diferentes atores sociais envolvidos com a comunidade escolar no sentido da manutenção do status quo na medida em que, para a ética religiosa, os caminhos do Bem e do Mal não se mesclam. Esses caminhos considerados verdadeiros impõem certos preceitos morais (como obediência e humildade) e adensam as articulações em torno de discursos conservadores. Importante ressaltar que o sistema normativo religioso está ancorado em leis universais que, num olhar desavisado, difere bastante do modo como a cientificidade dialoga com suas normas e princípios. No entanto, os discursos do sacerdócio e da cientificidade na FP se aproximam apesar do caráter antagônico que marcou a

\footnotetext{
${ }^{3}$ Esses documentos fazem parte do material empírico investigado na Tese de Doutorado em Educação (cf. BORGES, 2015).
} 
emergência/consolidação do pensamento cientificista no campo. Há consenso de que esse sistema normativo religioso influenciou sobremaneira a educação, mas também se observa uma crescente hegemonia do discurso da ciência que se apresenta para ocupar o lugar da religião. A partir da perspectiva discursiva (LACLAU, 2011, 1990), compreendo que um antagonismo se atualiza na disputa entre sacerdócio docente e profissionalização docente.

Cabe explorar certos sentidos que estão ligados ao cristianismo, mas que as relações não estão dadas por lógicas causais.

A segunda possibilidade de pensar a relação entre universalidade e particularidade está ligada ao cristianismo. O ponto de vista da totalidade existe, mas pertence a Deus, não a nós, de modo que não é acessível à razão humana. Credo quia absurdum. Assim o universal é um mero evento numa sequência escatológica, apenas acessível a nós por meio da revelação.

[...]como os desígnios de Deus são inescrutáveis, a camada profunda não pode ser um mundo atemporal de formas racionais, mas uma sucessão temporal de eventos essenciais que não podem ser captados pela razão humana; e, como cada um desses momentos universais tem de se realizar numa realidade finita que nada tem em comum com eles, a relação entre as duas ordens precisa ser opaca e incompreensível. Esse tipo de relação foi chamado de encarnação, cuja característica distintiva é a seguinte: entre o universal e o corpo que o encarna, não há qualquer vínculo racional. Deus é o único e absoluto mediador. Assim começava uma lógica sútil, destinada a ter profunda influência em nossa tradição intelectual: a do agente privilegiado da História, aquele cujo corpo particular era a expressão de uma universalidade que o transcendia. A ideia moderna de uma "classe universal" e as várias formas de eurocentrismo nada mais são do que os efeitos históricos longínquos da lógica da encarnação. (LACLAU, 2011, p. 51).

Acompanhando a afirmação de Laclau de que razão humana não compreende os desígnios de Deus e que a relação entre as duas ordens se expressa naquilo que se denomina encarnação, talvez seja oportuno compreender as relações que se estabeleceram/estabelecem no sacerdócio docente constituindo modos de subjetivação que valorizam o sujeito particular como aquele capaz encarnar o universal, como um agente privilegiado e capaz de perseguir a ordem instituída pelo universal. Qual o efeito desses traços de sentidos que se hibridizam/traduzem a outros reiterando aspectos da encarnação? Quais/como os deslocamentos para o imaginário social do sacerdócio ainda se apresentam (não do mesmo modo) e reverberam sentidos no fazer do professor? Quais são as repercussões desse discurso nas posturas conservadoras na docência? Mais do responder a essas questões gostaria de trazer outros fragmentos para entrar na disputa por sentidos de como esses nomes "sacerdócio docente”, "professor apóstolo", “missionário", “vocacionado” podem mobilizar diferentes forças dado o contexto radical no qual possam estar inseridos. 
No material investigado, Ferreira (2009), discute que a identidade docente é credora da imagem do professor apóstolo, libera-se "de posições políticas", envolve-se "com a reprodução de conhecimentos", oferece "serviço doado" retribuído pela sociedade da melhor forma possível, ainda que um "conhecimento básico para a subsistência” (FERREIRA, 2009, p. 286). Deslocamentos de sentidos como estes promovem reativações, parecem estar circunscritos desde sempre, mas operam por contingências e na condição precária e provisória dos processos hegemônicos. A autora postula ainda

Logo, dado que muitos docentes se considerariam profissionais de docência, os sindicalistas acreditam que esse termo, ao ser associado exclusivamente a uma concepção técnica da atividade, não permite perceber os aspectos políticos da educação e o resguardo no âmbito da vocação. Isto tem consequências: "ser apóstolo, mais que descrevê-lo teoricamente, é a atitude do professor em relação ao trabalho, como trabalha, como se envolve no trabalho; nisto se vê como apóstolo".

A professora se vê como, a professora torna-se, então: "uma espécie de sacerdotisa que devia transmitir, e que, pelo tipo de material com o qual trabalhava, que era as crianças, deveria manter-se em estado de pureza, isto é, não deveria contaminar-se com o que sucedia [...]; o conhecimento era neutro, e requereria, então, que aqueles que fossem seus transmissores deviam igualmente ser neutros. [grifo meu] (FERREIRA, 2009, p. 286)

Ferreira parece atentar que as estabilizações de sentido acerca do professor apóstolo se traduzem em modos de subjetivação dos professores. Na minha interpretação isso evidencia que a tentativa de preencher de uma vez por todas a identidade docente, mostra-se sempre como um adiamento. Isso significa ainda que não há uma única identidade cujo efeito seja o preenchimento desse lugar vazio sem que este seja interpelado por forças em disputa. Qualquer processo de identificação (não a identidade fixa), ao preencher um espaço através de um conteúdo (qualquer conteúdo), é/está inadequado para esse preenchimento. A identificação é sempre constituída pela incompletude e será sempre contingencial (LACLAU, 1994).

Por outro lado, ainda que esses processos sejam traduzidas sempre de forma incessante, certas estabilizações encontram passagem e seguem numa tentativa de conformação dos indivíduos ao (que se considera) ideal de projeto social (sedimentação). Tais fixações seguem na tentativa de estabelecer relações as quais os indivíduos possam espelhar o projeto social vigente, numa concepção clássica de representação e contribuindo sobremaneira para o fortalecimento de discursos conservadores da/na educação.

Sônia Lopes apresenta indícios dessa representação que ainda emerge no cenário atual 
$\mathrm{Na}$ verdade, tanto no Brasil como em Portugal, almejava-se formar um professor culto, conhecedor de seu ofício, portador de uma cultura científica e pedagógica aprofundada. Mas ao mesmo tempo queria-se um professor "missionário" ao serviço da estabilidade do regime e da ordem social instituída. Por isso, em ambos os países, a conduta social, política e religiosa dos candidatos ao magistério possuía muito peso na admissão às escolas normais. [Grifo meu] (LOPES, 2012, p. 273).

Trata-se de uma articulação hegemônica no campo de formação de professores que ora bloqueia, ora mantém essa lógica de que o professor pode estar a serviço da manutenção da ordem social constituída, edificando a lógica conservadora na educação. A autora parece insinuar certa surpresa com relação à demanda brasileira e portuguesa por "um professor culto, conhecedor de seu ofício, portador de uma cultura científica e pedagógica aprofundada" e também demandar "um professor "missionário" ao serviço da estabilidade do regime e da ordem social instituída". Temos a expansão da cadeia discursiva na qual cabe tanto a "razão", nesse caso a razão científica (repelida pelo sacerdócio) como temos ainda a ideia de um professor cuja tarefa seja "encarnar" a missão previamente dada visando a continuidade de uma ordem estabelecida. Tais movimentos tropológicos apontam para disputas mais amplas que tendem a gerar conflitos - o caso da tensão entre forças conservadoras e forças progressistas que se reapresentam nos mais variados discursos pedagógicos.

Conecto essa interpretação acima às afirmações de Ernesto Laclau de que pode haver um hiato na sucessão de deslocamentos e condensações. Seus efeitos se realizam quando se vai além do sentido literal. Há uma interrupção que possibilita a emergência de um espaço de indeterminação que assume um papel constitutivo apontando para a afirmação de que nenhuma lógica apriorística pode governar o social (LACLAU, 2006, p. 86-91).

Sedimentar passa por estabelecer/reconhecer as relações antagônicas que possibilitaram certa nomeação/representação. No caso do sacerdócio docente o limite (relação antagônica), implica a capacidade ou não de encarnar/de se doar aos preceitos divinos ou vocacionais sem restrições. Acatar esse dom interior que clama por sua emergência, que impele a ações (promove subjetivações) significadas como entrega, doação, amor ao outro, respeito, obediência e, assim, favorece a manutenção da ordem social instituída (rastros do pensamento conservador). Nessa medida um professor encarna preceitos da ordem instituída, se subjetiva e é subjetivado como sendo um "eu” espelho do social. Mais do que isso, empreendem-se práticas discursivas com vistas a estabilização de algo da ordem do impossível - há um esforço em projetar modos de ser/modos de viver/modos de sentir sustentados por fundamentos previamente dados, estabelecem-se crivos, 
guardiães das normas buscando o sentido correto (sustentado pelo Bem), há necessidade de definições previamente dadas que idealmente serão reconhecidas - status quo, por excelência.

Com a pretensão de discutir a profissionalização docente julgo importante argumentar que o principal bloqueio que o sacerdócio docente confere é o bloqueio à razão. Não qualquer razão, mas aquela que queira esclarecer/elucidar os desígnios de Deus. Levando em conta os caminhos permeados sob a influência religiosa e as interpretações da religião pelo social, essa noção chega ao campo da Formação de Professores por deslocamentos de sentidos/significantes. Por respostas simbólicas como a possibilidade de que professores ou leigos, desde que vocacionados para se entregarem aos desígnios de Deus (traduzidos nos preceitos da moral e bons costumes), possam exercer a atividade docente. $\mathrm{Na}$ investigação realizada, com o aporte teórico discursivo, um dos destinos dessa apropriação de sentidos se apresenta no exercício do sacerdócio docente que valora práticas educativas visando a manutenção do status quo, traços do pensamento conservador. Essa faceta do fazer docente é fortalecida por lógicas identitárias que compõem o cenário educacional e respondem ao antagonismo afirmando identidades fixas/centradas ligadas ao bom cristão como tolerância, obediência, não questionamento de certas leis universais, boa conduta, respeito à autoridade, crença, aceitação das regras morais.

\section{A PROFISSIONALIZAÇÃO DOCENTE REPELE O SACERDÓCIO: O "EU" SEGUE SENDO A REPRESENTAÇÃO DO SOCIAL}

Consolida-se uma relação antagônica entre profissionalização docente e sacerdócio docente no momento em a profissionalização docente passa a circular como hegemônica no campo de formação de professores. No que se refere mais propriamente a aspectos teóricos, vale destacar alguns importantes elementos introduzidos por um corte antagônico - a negatividade, a falta, o fracasso - que interpelam a compreensão do social/da sociedade a partir de qualquer positividade ou essencialismo. O antagonismo revela limites do social, ou ainda, as fronteiras políticas de uma formação social. Além disso, evidencia aspectos nos quais a identidade não pode ser estabilizada no sistema diferencial de significação e evidencia como ela é contestada pelas forças que se colocam no limite dessa ordem (LACLAU, 2011).

Assim, a cadeia discursiva do sacerdócio docente aprofunda o ideal educacional a partir da manutenção da ordem estabelecida, adensando discursos conservadores. Por outro lado, a cadeia discursiva da profissionalização docente vai se constituir a partir de articulações com outros discursos que promovem a ideia de inconformidade com a realidade social e com a busca por estratégias para transformá-la, o que se articula ao fortalecimento de discursos mais progressistas. 
Um importante aliado nessa disputa são os discursos acerca das racionalidades científicas e técnicas. Ambas promovem o rebaixamento da ideia de que, ao professor, basta exercer sua vocação (desde sempre presente), ou ainda, de que ele seja esse agente privilegiado que encarna os princípios do bom professor ancorado nos preceitos religiosos.

Ao longo do século XIX, vai se consolidando uma imagem de professor, consubstanciada em uma concepção de magistério tido como sacerdócio, apostolado, construída nos longos anos, nos quais a Igreja Católica teve o monopólio educacional e que foi preservada, mesmo com Proclamação da República e a consequente extinção do Padroado. Nessa perspectiva, privilegia-se, por um lado, a valorização dos atributos humanos e, por outro, uma visão da "profissão" docente segundo o qual os professores não deveriam saber demais, nem de menos, não deveriam ser pobres, nem ricos e não se constituíam nem como profissionais liberais, nem como funcionários. (DUBAR apud PASCHOALINO, OLIVEIRA, ROCHA, 2011, p. 82).

Em síntese, os "professores seja como corpo eclesial, ou corpo estatal ficaram subordinados a organizações e a poderes mais fortes, que os associam a simples executores. (TARDIF, 2005, p. 23 apud PASCHOALINO, OLIVEIRA, ROCHA, 2011, p. 83).

Um primeiro movimento, nesse jogo de disputas por significação, que possibilitou a ampliação da cadeia discursiva em prol da profissionalização docente foi a passagem de controle da Igreja para o Estado. Entre outras questões, isso implica em uma mudança na concepção de mundo que, na dimensão religiosa, tende a ser circunscrita por leis divinas já previamente determinadas por algo/Deus e leva a uma relação de completa exterioridade. No modelo estatal essa relação de exterioridade ainda se mantém, pois o modo de se relacionar com os professores passa por colocá-lo em um lugar já demarcado e de exterioridade. Não obstante, outras formas mais flexibilizadas são permeáveis nesse modelo. Isso possibilita, em geral, mais espaços para questionamentos o que pode levar a uma vinculação com posições ditas progressistas.

Se havia o domínio dos preceitos religiosos cristãos, apoiados no humanismo e, aliado a isso, à ideia de manutenção e ampliação desse cultivo da civilização via humanização/cristianização da sociedade como um todo e na área educacional em particular, ocorre um deslocamento para o conflito de interesses com relação ao que se almeja para a sociedade - a ideia da transformação/mudança do sociedade emerge em vários campos de saber com ampla disseminação. Outros modelos de homem/sociedade pedem passagem. Dentre os vários elementos que compõem esse cenário, ressalto o avanço crescente do discurso científico - um importante fator nesse sentido e que tende a afastar discursos religiosos/humanistas cultivados, tanto pelo senso comum como pela comunidade epistêmica. Outra marca fundamental a ser considerada e que se apresenta junto à tutela do estado, refere-se ao controle gerado a partir da sua ancoragem em leis e normas 
burocráticas (VIEIRA, HYPÓLITO, DUARTE, 2009, p. 226). Por outro lado, o discurso em defesa da tradição, mais um elemento a ser considerado, funciona como um "porto seguro" diante das transformações que, em geral, geram insegurança e resistência entre os docentes.

Aqui a tradição imaginada cumpre seu papel de controle, valendo-se da repetição (das experiências, das leis: as leis sempre são lembradas), e funcionando como uma crença que tem efeito de doutrinação simbólica, produzindo mecanismos que retiram a autonomia intelectual do professorado. Em nome da tradição - da coesão - do grupo, constitui-se então um modelo de controle talvez mais poderoso e mais insidioso sobre o trabalho docente, confundindo as tentativas de inovação das professoras com falta de experiência, ingenuidade, incompetência ou adversidades culturais. Nesse processo, prevalece a ideia de magistério como uma vocação (e sacerdócio) que nem todos possuem, mas que devem perseguir, por meio de exemplos de perseverança, fé e entrega pastoral. (p. 228).

Vale destacar que a tradição é aqui compreendida como herança cultural, legado de heranças transmitidas. A ideia de transmissão ou de entrega de fatos, lendas, ritos, usos, costumes busca produzir certa coesão moral no corpo social. seu caráter quase sempre doutrinal ou dogmático, proferido pelo mais antigo ou pela autoridade, procura garantir a continuidade das experiências já vividas, funcionando como uma espécie de eco, perpetuando hábitos e costumes adquiridos e tornados rotina. Numa palavra: naturalizados. (p. 231).

Tendo em vista a recorrência com que a tradição é evocada quer por autores do campo de Formação de Professores, quer pelas entidades de educadores, pelos professores ou pelas pessoas comuns, não se pode deixar de atentar que tais deslocamentos carreiam sentidos dos discursos religiosos cristãos (fé, caráter doutrinal, autoridade de quem encarna a tradição) e empreendem tensionamentos ao caráter liberal/progressista/transformador que se apresenta e mobiliza disputas nas discussões sobre o caráter profissional (asséptico, científico, neutro) da profissão docente. Segundo alguns autores (LUDKE, BOING, 2010) essa é uma peculiaridade do campo educativo que carrega essa ambiguidade em sua profissionalidade, enquanto outras profissões como médicos assumem com mais desenvoltura a condição de profissional liberal, independente, autônomo e altamente normatizados.

Com todos esses elementos paradoxais, compreendo que a profissionalização docente tem sua emergência nesse cenário em que o estado exerce a tutela sobre o professor. Essa me parece ser uma contingência que cria as condições de articulação discursiva, certo estancamento (fixação/estabilização) de sentidos em torno desse dinâmico processo de significação. Um efeito desse processo envolve a mediação dos processos educativos e a normatização das atividades docentes em nome do Estado. 
Os professores, como grupo profissional, têm uma história específica, conforme mostra Nóvoa (1995). Ele fala do caso português, mas praticamente tudo o que diz serve para o Brasil, uma vez que o nosso desenvolvimento escolar seguiu a matriz da metrópole portuguesa. Antes, o modelo de professor era o religioso, envolvendo a docência numa aura de vocação e sacerdócio, mesmo em se tratando de professores leigos. A estatização foi um passo rumo à profissionalização, porque significou o rompimento dessa relação vocacional. No entanto, segundo Nóvoa, o processo de estatização não foi capaz de levar adiante a construção de uma codificação deontológica da profissão, como têm as profisssões liberais atuais. A explicação do autor para esse fato se dá pela imposição, na estatização, de instituições mediadoras da regulamentação docente. As inspetorias de ensino, para citar uma das mediações, sempre exerceram um controle reconhecido sobre o exercício formal da docência. E os docentes sofrem o processo de "funcionarização". Esta falta de autonomia do professorado coloca em dúvida a existência de uma "profissão" docente. Quando muito, podemos falar de um processo de profissionalização. (LUDKE, BOING, 2007, p. 1173).

O que se depreende dessas questões levantadas pelos autores é que o Estado fracassou em sua pretensão de empreender a profissionalização docente. Vale destacar que vários autores de referência nas políticas curriculares para formação docente, seguem essa linha de raciocínio: Helena de Freitas (2003) que fala em desprofissionalização, Maurice Tardif utiliza o termo semi-profissão, além de outros que questionam a profissionalização atrelada a certificação como Iria Brzezinski (2008). Destaco neste fragmento outra afirmação que considero importante explorar/des-sedimentar - o processo de estatização não foi capaz de levar adiante a construção de uma codificação deontológica da profissão. Este destaque se justifica por que, ao explorar essa ideia de construir uma codificação deontológica para a profissão docente, encontro vários embates que emergem tanto no âmbito das entidades de educadores, como entre os especialistas da área, ou nos textos oficiais (“ditos"governamentais), entre outros.

Quando enuncio que "o "eu" segue sendo a representação do social", a meu ver, indico que minha argumentação segue no sentido de defender que discursos da profissionalização docente ressoam nas políticas curriculares para a formação docente marcadamente na tentativa de construir um "eu" (identidade) para o futuro professor. Isso se apresenta nas políticas curriculares de variadas formas por que essa é uma das condições de possibilidade de qualquer prática político/discursiva empreender suas disputas em "sua" superfície de inscrição. No entanto, há marcas que seguem como se fossem as fixações "necessárias" de dado campo discursivo (neste caso, o educativo). Afirmo que no caso desta investigação os variados discursos privilegiam a identidade docente como garantia de um projeto social mais amplo para a sociedade. Vale destacar que, no que se refere ao sacerdócio, o princípio básico envolvia aspectos morais, religiosos e humanistas. E no caso da 
profissionalização? Aspectos religiosos foram distanciados com o fortalecimento do estado laico e do discurso científico. Mas, o que dizer dos outros aspectos? Não havendo nenhuma força antagônica capaz de expulsá-los da cadeia de significação, esses sentidos encontram passagem na tentativa de definir o que é ser professor a partir da profissionalização docente. Sendo assim, os discursos conservadores em seus aspectos morais continuam fortalecidos quer sejam pela tradição ou quer sejam por tentativas de normatização. O discurso humanista (BIESTA, 2006) se associa ao discurso racionalista explorando a ideia cartesiana do "penso logo existo" e considera os atores sociais a partir do princípio da racionalidade.

Apoiada na teoria do discurso (perspectiva discursiva), defendo que a estabilização ou não de qualquer discurso vai se dar a partir da condição de engendrar configurações plausíveis a um fenômeno social: o político. Esta investigação teórico-estratégia buscou fazer (re)leituras, interpretações das lógicas dominantes em discursos da formação de professores, reativando interpretações de como estas lógicas podiam ser lidas como obliterantes, ainda que sejam marcadas pela indecidibilidade como propõe a Teoria do Discurso (HOWARTH, 2000, p. 134-135).

Tendo em vista essa compreensão do político, as tentativas de construção de uma codificação deontológica da profissão docente parece ser uma iniciativa valorizada por várias "correntes" dentro do campo de formação de professores sempre com o objetivo de definir, defender e justificar certos princípios-chave que "pretensamente" são os princípios os quais os sujeitos, sua profissão, sua psique, a educação ou a sociedade devem ser estruturados (idem, p. 130).

\section{CONSIDERAÇÕES FINAIS}

Operar com a perspectiva discursiva neste processo de investigação permitiu reativar sentidos que tendem a ser inviabilizados nos processos discursivos das políticas curriculares para a formação de professores. Nesse sentido, considero que posturas conservadoras nunca deixaram de projetar modos de representação com caráter universal, fazendo-se parecer razoável. Invocando a seu favor um campo de discursividade com maior amplitude (discursos do imaginário social) para seguir fazendo valer os pensamentos instituídos, as práticas docentes conservadoras.

Conforme foi pontuado nas seções anteriores, a formação docente vem sendo vinculada à profissionalização docente e este foi um importante antagonista ao discurso de professor leigo sustentado pela cadeia discursiva do sacerdócio docente. No entanto, esses deslocamentos de 
sentido não foram capazes de rejeitar posturas conservadoras, apesar de defenderem sua vinculação com posições ditas progressistas.

Seguindo na linha de argumentação do texto, considero que proposições conservadoras seguem, desde sempre, disputando no campo das políticas curriculares para formação de professores.

Argumentei, neste trabalho, a partir do discurso do sacerdócio e da profissionalização docente, que as lógicas conservadoras disputam sua hegemonia nas políticas curriculares amplificando seu discurso, fazendo diferentes articulações e exercendo flutuações de sentido, via remetimento de significantes para significantes.

Esta investigação que teve como mote colocar em marcha os sentidos (significantes), possibilita-me a compreender que as práticas discursivas não operam por superação de ideias/conceitos/modos de conceber o mundo. Sendo assim, o pensamento conservador mantém-se no jogo político. Irrompe, via diferentes atravessamentos, sem respeitar lógicas racionais previamente dadas, um "eu”, que pode ser qualquer um de nós, propaga seus princípios. Cabe-nos o exercício de seguir intervindo, propondo sem considerar que esta intervenção e/ou proposta será uma última palavra a este respeito. A afirmação lacaniana "sou onde não penso", talvez possa nos dar pistas que abalem nosso apego às formas já instituídas de conceber o mundo e talvez possa dar mostras de que não há possibilidade de encontro com uma sociedade reconciliada. 


\section{REFERÊNCIAS}

BIESTA, G. Beyond Learning: Democratic Education for a Human Future. London: Paradigm, 2006.

BORGES, V. Espectros da profissionalização docente nas políticas curriculares para formação de professores: um self para o futuro professor". Tese (Doutorado em Educação) - Faculdade de Educação, UERJ, Rio de Janeiro, 2014.

BALL, S. What is policy? Texts, trajectories and toolboxes. In: Education Reform: A critical and poststructural approach. Buckingham: Open University Press, 1994.

BIGLIERI, P.; PERELlÓ, G. Los usos del psicanálisis en la teoria de Ernesto Laclau. Buenos Aires: Grama, 2012.

BOING, L.; LUDKE, M. O trabalho docente nas páginas de educação e Sociedade em seus (quase) 100 números. Educ. Socied., vol. 28, n. 100, Especial, p. 1179-1201, out. 2007.

Profissionalidade docente. In: OLIVEIRA, D.A.; DUARTE, A.M.C; VIEIRA, L.M.C. Dicionário: trabalho, profissão e condição docente. Belo Horizonte: UFMG/ Faculdade de Educação, 2010. CDROM.

BRZEZINSKI, I. Políticas contemporâneas de formação de professores para os anos iniciais do ensino fundamental. Educação e Sociedade, vol. 29, n. 105, p. 1139-1166, set./dez. 2008.

CORREIA, W.F. O que é conservadorismo em educação? Conjectura: Filos. Educ., Caxias do Sul, v. 18, n. 2, p. 78-90, maio/ago. 2013.

CRAVEIRO, C. Políticas curriculares para formação de professores: processos de identificação docente (19952010). 2014. Tese (Doutorado em Educação) - UERJ, Rio de Janeiro, 2014.

CUNHA, E.; LOPES, A.C. Organização curricular em áreas do conhecimento: o nome da política curricular de ciclos em Rondonópolis-MT. Revista e-Curriculum, São Paulo, n. 11 v. 03 set./dez. 2013. Disp.: < http://revistas.pucsp.br/index.php/curriculum>.

LOPES, A.C.; COSTA, H. Da Recontextualização à Tradução: investigando políticas de currículo. Currículo sem Fronteiras, v. 13, n. 3, p. 392-410, set./dez. 2013.

DIAS, R.E. Política curricular de formação de professores - um campo de disputas. Revista e-Curriculum, v. 8, p. 1$21,2012$.

GATTI, B.; BARRETO, E.; ANDRÉ, M. Políticas docentes no Brasil. Brasília: Unesco, 2011.

FINK, B. O sujeito lacaniano. Rio de Janeiro: Zahar,1998.

HOWARTH, D. Discourse. Open University Press: Buckingham, Philadelphia, 2000.

LACLAU, E. Política de la retórica. In: Misticismo, retórica y política. Buenos Aires/México: Fondo de Cultura Económica, 2006. p. 57-127.

. New Reflections on the revolution of our time. London: Verso, 1990.

Emancipação e Diferença. Rio de Janeiro: EdUERJ, 2011.

; MOUFFE, C. Hegemonía e estrategia socialista. Hacia radicalización de la democracia. 3. ed. Buenos Aires: Fondo de Cultura Económica, 2010.

LOPES, A. C.; MENDONÇA, D. (Orgs.). A teoria do Discurso de Ernesto Laclau. São Paulo: Annablume, 2015.

; MACEDO, E. Teorias do Currículo. São Paulo: Cortez, 2011.

<www.scielo.br>.

Democracia nas Políticas de Currículo. Cadernos de Pesquisa, v. 42, p. 700-715, 2012. Disp.:

; MACEDO, E.; TURA, M. de L. As representações sociais e os estudos de política de currículo para formação docente. In: PLACCO, V.M.N.; VILLA BÔAS, L.P.S.; SOUSA, C.P. (Orgs.). Representações sociais: diálogos com a educação. São Paulo: Champagnat/FC, 2012 v. 109-136.

; BORGES, V. Formação docente, um projeto impossível. Cadernos de Pesquisa, v. 45, p. 486-507, 2015.

MACEDO, E. Currículo e conhecimento: aproximações entre Educação e Ensino. Cadernos de Pesquisa, v. 42 n. 147 p. $716-737$ set./dez. 2012. 
MARCHART, O. Post-foundational political thought: political difference in Nancy, Lefort, Badiou and Laclau. Edinburgh: Edinburgh University Press, 2007.

NÓVOA, A. (Org.). Profissão professor. Porto: Porto Editora, 1991.

(Coord). Os professores e a sua formação. 2. ed. Lisboa: Dom Quixote, 1995. 158 p.

OLIVEIRA, A. Políticas de currículo: lutas por significação no campo da disciplina História. 2012. Tese (Doutorado em Educação) - UERJ, RJ, 2012.

VIEIRA, J.; HYPOLITO, A.; DUARTE, B.G. Dispositivos de regulação conservadora: currículo e trabalho docente. Educação \& Sociedade, v. 30, n. 106, 2009.

STAVRAKAKIS, Y. Lacan y lo politico. Buenos Aires: Prometeo libros, 2007.

\section{Material empírico: Artigos selecionados}

AQUINO, J. G.; MUSSI, M. C. As vicissitudes da formação docente em serviço: a proposta reflexiva em debate. Educ. Pesquisa, v. 27, n. 2, jul./dez. 2001.

BODIÃO, I.S.; FORMOSINHO, João. A profissionalidade docente na educação básica em Portugal: depoimento de alguns professores. Educação e Pesquisa, v. 36, p. 403-418, 2010.

CHAKUR, C.R.S. O desenvolvimento profissional de professores das séries iniciais do ensino fundamental. Paidéa, 15(32), p. 397-407, 2005

CONTRERAS, S.; GLADYS, A.; VILLALOBOS CLAVERÍA, A. La formación de profesores en Chile: una mirada a la profesionalización docente. Educación y educadores, vol. 13, n. 03, p. 397-417, 2010.

CUNHA, M.I.; RIGO, A.M.R.; PINTO, C.L.L.P.; VOLPATO, G.; FERNADES, S.R.S.; CHAIGAR, V.A.M. Autonomia e autoridade com a teoria e a práctica: o caso da profissão docente. Educação, v. 29, n. 2, p. 67-84, 2004. Disp.: <http://www.ufsm.br/ce/revista>. Acesso: 30 maio 2013.

FERREIRA, M. O. V. Discutir educação é discutir trabalho docente: o trabalho docente segundo dirigentes da CTERA. Revista Brasileira de Educação, v. 14, n. 41 maio/ago. 2009.

FOERSTE, E. Parceria na licenciatura: fortalecendo lutas pela profissionalização docente. Geografares, UFES, n. 04, p. 21-30, 2003.

FREITAS, H. A certificação docente e formação do educador: regulação e desprofissionalização. Educ. Soc., Campinas, v. 24, n. 85, p. 1095-1124, dez. 2003.

ITO, L.H. Projeto do futuro e identidade: um estudo com estudantes formandos. Revista Aletheia, p. 65, jan. 2008.

LOPES, A.C.; DIAS, R.E. Competências na formação de professores no Brasil: o que (não) há de novo. Educ. e Soc., v. 24, n. 85, p. 1155-1177, dez. 2003. Disp.: <http://www.cedes.unicamp. br>. Acesso: 30 maio 2013.

LOPES, S.C. Formação e profissionalização docente no Brasil e Portugal em fins do século XIX: Apontamentos para uma história da educação comparada. Revista Teias, Rio de Janeiro, v. 14, n. 28, 265-277, maio/ago. 2012.

LUIS, H.; CAMPOS, J.; FIGUEIREDO, M.; ROLDÃO, M. O conhecimento profissional dos professores especificidade, construção e uso: da formação ao reconhecimento social. Revista Brasileira de formação de professores, vol. 1, n. 2, p. 138-177, set. 2009.

MONCEAU, G. Transformar as práticas para conhecê-las: pesquisa-ação e profissionalização docente. Educação e Pesquisa, São Paulo, vol. 31, p. 467-482, 2005.

MORGADO, J. Identidade e profissionalidade docente: sentidos e (im) possibilidades. Ensaio: aval. pol. Públ. Educ., Rio de Janeiro, v.19, n. 73, p. 793-812, out./dez. 2011.

OLIVEIRA, D.A. Os trabalhadores da educação e a construção política da profissão docente no Brasil. Educar em Revista, Curitiba, n. especial, p. 17-35, 2010.

PASCHOALINO, J.B.; OLIVEIRA, M.A.M.; ROCHA, T.C. Políticas para o Ensino Superior: Profissionalização ou proletarização do trabalho docente? Trabalho e Educação, Belo Horizonte, v. 20, n. 2, p. 77-89, maio/ago. 2011.

PACHECO, J. A (difícil) construção da profissionalidade docente. Educação, Santa Maria, v. 29, n.2, p. 11-25, 2004. Disp.: <http://www.ufsm.br/ce/revista>.

SCHUELER, A. F. Representações da docência na imprensa pedagógica na Corte imperial (1870-1889): o exemplo da Instrução Pública. Educação e Pesquisa, São Paulo, vol. 31, p. 379-390, 2005. 
SOARES, A.C.; LOGUERCIO, R.Q.; FERREIRA, M. A possibilidade de produção de saberes docentes na EJA/RS. Revista Eletrônica de Educação, vol. 5(1), p. 3, 2011.

WEBER, S. Profissionalização docente e políticas públicas no Brasil. Educ. e Soc., v. 24, n. 85, p. 1155-1177, dez. 2003. Disp.: <http://www.cedes.iunicamp. br>. Acesso: 30 maio 2013.

\section{RESUMO}

Este artigo decorre de uma investigação a partir dos significantes sacerdócio e profissionalização docente. O enfoque teórico-estratégico ampara-se na teoria do discurso (TD) de Laclau e Mouffe incorporada ao campo do currículo por Lopes e Macedo. Tem como foco os deslocamentos de sentidos nos discursos conservadores nas políticas curriculares. Discute como as cadeias discursivas do sacerdócio docente se antagonizam à de profissionalização docente. Defende que os significantes, que dão sustentação às práticas discursivas docentes, operam por deslocamentos que subjetivam e são subjetivados em suas tentativas de projetar um "eu" para o professor.

Palavras-chave: conservadorismo, profissionalização, currículo, discurso.

\section{CONSERVATIVE DISCOURSES ON CURRICULUM POLICIES: FROM PRIESTHOOD TO TEACHER PROFESSIONALIZATION}

\section{ABSTRACT}

This article stems from an investigation from the significant priesthood and teacher professionalization. The theoretical and strategic approach to seek refuge in discourse theory (TD) of Laclau and Mouffe incorporated into the curriculum field by Lopes and Macedo. It focuses on the senses shifts in conservative discourses in curriculum policies. Argues how the discursive chains of teaching priesthood antagonize the professionalisation of teaching. It discusses that the signifiers that support the discursive teaching practices operate by displacements subjectify and are subjectified in their attempts to design a "self" for the teacher.

Keywords: conservatism, professionalization, curriculum discourse.

Submetido em Set./2016 Aprovado em Dez./2016 